\title{
Design of closed-loop control for Solar PV based Multi-Level Inverter
}

\author{
P.Guruvulu Naidu, S.Satyanarayana, Ch.Saibabu
}

\begin{abstract}
Photovoltaic (PV) based multilevel inverters (MLI) have emerged as one of the best alternatives for grid/standalone applications. MLIs offer high range power handling capability with low current and voltage distortion and lesser switching losses as compare to the traditional two-level inverter. Major challenges with generally used multilevel inverter topologies relates to capacitor voltage variation, modulation techniques, and control. The major center of attention of research in this paper is to build up sophisticated modulation and voltage balancing methods for multilevel inverter topologies, competent to reach capacitor voltage parameter and to decrease power switching losses of the inverters. The present paper focuses on closed-loop control of multilevel flying capacitor inverter (FCI). In FCI, the phase shift (PS) based pulse width modulation method is designed and investigated. The closed-loop controller is designed with input voltage control of MLI, whose source is solar PV based Boost converter. Reported simulation results prove the superiority of the closed loop control in maintaining the desired output voltage for various reference values.
\end{abstract}

Keywords: Multi-Level Inverter, Phase-shifted Pulse-width modulation (PWM), Closed-loop control, Boost converter, Solar Photovoltaic.

\section{INTRODUCTION}

Modern semiconductor devices lead to the use of multilevel inverters in high range power electronic devices application. In this, the major problem of the taditional two-level power electronic inverter is the requirement of a huge number of power electronic devices connected in parallel and/or series in the direction of is competent to arrangement with high voltage/currents. These associations may generate over-voltages and/or over-currents to the power devices proper to their different characteristics. Additionally, outsized filtering components are essential for the reason with the purpose of the small feature of the output voltages. On the other hand, it will also add to the switching power losses of the inverter. All these problems are less considerable while using MLI. Multilevel inverters permit high power devices usage potential with condensed harmonics as well as low switching power losses while compared through the two-level matching part. Here Multilevel inverters be capable of development large amounts of power, this is why these topologies are attractive all the rage in applications such as outsized scale wind and solar photovoltaic power plants. Even though the multilevel conversion technology is comparatively

Revised Manuscript Received on December 13, 2019.

* Correspondence Author

P.Guruvulu Naidu, PhD scholar, Department of EEE, J.N.T.U University, Kakinada, Andhra Pradesh, India

Dr.S.Satyanarayana,Professor, Department of EEE, Raghu Institute of Technology, Visakhapatnam, Andhra Pradesh, India

Dr.Ch.Saibabu, Professor, Department of EEE, J.N.T.U University, Kakinada, Andhra Pradesh, India

grown-up, various improvements preserve be prepared to these complex topologies. Various do research areas are the control of the voltages in the capacitors, and the enhancement of efficiency and reliability. Electrolytic capacitors are generally used in multilevel inverters; on the other hand, these components have a somewhat short lifespan. This is why they are being replaced by thin-film capacitors, which offer a slighter capacitance but a better life. The use of small capacitors implies closer control loops, as well as the voltage balancing loops. Additionally, the switching frequency of power inverters is likely to get higher shortly for the reason that of the use of the innovative wide-gap semiconductor devices, such as those based on silicon carbide (SiC). Higher switching frequencies involve in addition quicker and more efficient control loops. The multilevel inverter based on flying capacitors (FCs) topologies, i.e. in first case, flying capacitor inverter (FCI) device and second case stacked multi-cell inverter (SMC), have been paying attention including easier expansion to a quantity levels are higher than three (n greater than 3), while compared to diode clamped inverter (DCC) devices. Moreover, voltages in the FCs included into the topologies can be controlled on a per-phase basis dissimilar in the DCC, where all the phases influence the capacitor voltages. Even if there are various research publications on the multilevel FCI topologies, there are motionless a few aspects that have need of promote awareness. The most important research areas are the progress of computationally efficient modulation and voltage balancing techniques capable to make available solid FC voltages, the decrease of switching losses and capacitor voltage ripples, and the most important pre-charging of the FCs. Hence, this paper has been focused on all these topics.

\section{MULTILEVEL FCI}

Multilevel inverters have gained major attention here medium and high power electronic devices. By using power semiconductor devices based multi-level inverter circuits bear more voltage and power quaintly, lesser total harmonic distortion value, along with lesser losses with respective to the usual two-level inverter [1-2]. Along with various the multi-level inverter topologies, the mainly accepted methods are the Cascaded H-Bridge Inverters (CHBC) ,Modular Multilevel Inverter (MMC), DCC , and FCI [3]. Designed for the three-level FCI, the be in command of the FC voltages be comparatively easy; it be able to performed separately per every phase by purely irregular the two offered unnecessary switching states. An analogous voltage matching process is able in the direction of be apply to FCIs through an elevated quantity of levels ( $\mathrm{n}$ greater than 3 ). 
On other hand, during this case, here a new unnecessary condition to compact with, additional FC voltages are to be restricted. Every unnecessary state produces unusual things of the capacitor voltages on the charging/discharging. Afterward, calculating the voltages from corner to corner the capacitors is a challenging in MLI inverter.

Here FCI has gained major awareness for the reason that of its enhanced show while complete to a elevated quantity of number (n greater than 3), with respective the DCC. In addition, the FCI offers some dc to dc applications such as a HVDC inverters, VAR compensator and hybrid electric vehicle (HEV) as it provide good output performance, efficiency, output voltage and current[4]. On the other hand, there are various issues on the subject of the FCI which require to be measured during operating period of the various stage, while the early across FC charging, the capacitor voltage has ripples and reconfiguration for the period of faults, absolute voltage level process and voltage balance of the FCIs. A quantity of work regarding the reconfiguration and the comprehensive voltage level procedure was reported in [7].

Multilevel inverters contain major importance in medium and high power electronic devices such as motor drives, power generation, and distribution, power quality, and power conditioning. This is for the reason that power electronic multi-level inverter methods allow more voltage or power, produce voltages with low THD, as well as have low power losses with respective to the usual two-level inverter. However, multilevel inverters need a more number of power electronic switching devices and as a result their control becomes difficult and complex. In addition, they have need of a number of dc voltage sources which are frequently provided by capacitors. The capacitor voltages require to be balanced, which is demanding, especially for inverters with a large number of levels.

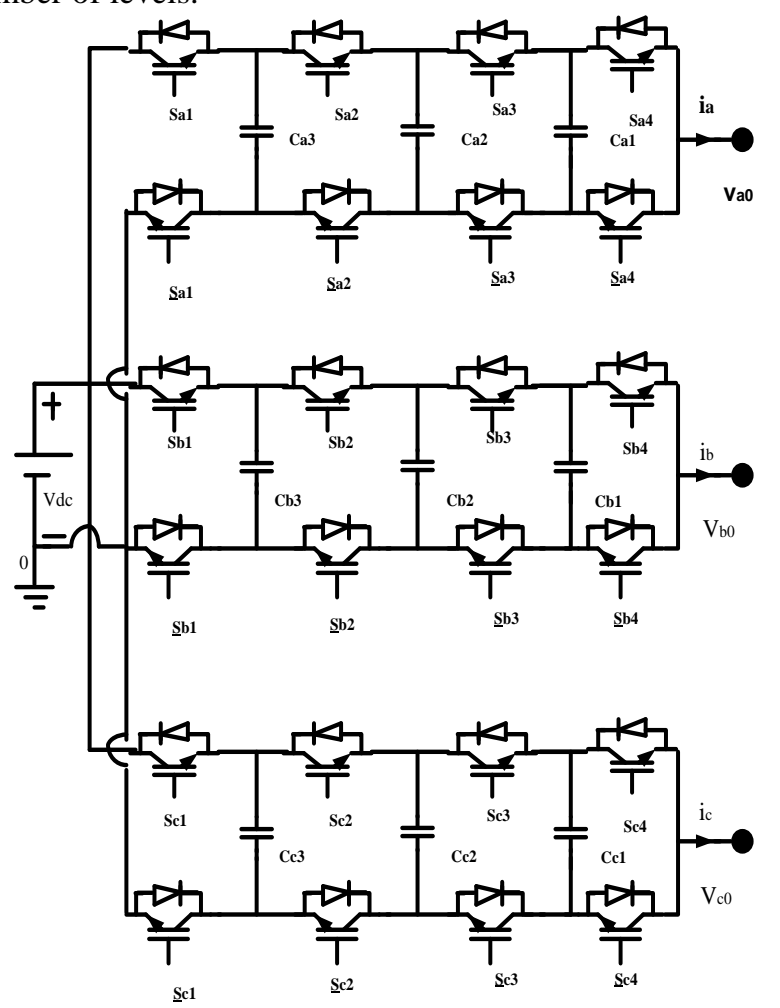

Fig.1 Three-phase five-level FCI inverter

The mainly conventional multilevel inverter topologies are viz. CHBC, MMC, DCC, FCI and
SMC. This paper is paying attention on the FC multilevel topologies, i.e. the FCI.These topologies are discussed in detail, at the same time as the other ones are discussed in a few words. In 1991, a single-phase, series connection of full-bridge inverter was accessible in [5] and used for a plasma stabilization application. Afterward, the proposal was absolute to consist of three-phase systems. The basic three-phase three-level and n-level structures used in the cascade inverter. The MMC was first projected in [4] and it has already been used in an HVDC application by Siemens. The DCC was introduced in [6]. The FCI was introduced in [7].

Figure 1 show a three-phase five-level FCI inverter, here three FCs be included with every phase-leg. for the duration of usual procedure, the stand for voltage values of the FCI inverter $\mathrm{C}_{\mathrm{x} 1}, \mathrm{C}_{\mathrm{x} 2}$, and $\mathrm{C}_{\mathrm{x} 3}$, for $\mathrm{X}=[\mathrm{a}, \mathrm{b}, \mathrm{c}]$, should be maintained at $\mathrm{V}_{\mathrm{dc}} / 4, \mathrm{~V}_{\mathrm{dc}} / 2$, and $3 \mathrm{~V}_{\mathrm{dc}} / 4$, correspondingly, where $\mathrm{V}_{\mathrm{dc}}$ is Dc link voltage from boost converter output voltage . In this circuit topology, here maximum voltage apply to every switching operating state is one-fourth of the dc-link voltage $\left(\mathrm{V}_{\mathrm{dc}} / 4\right)$. The switching state control utility is $S_{x y}$, here $\mathrm{y}$ defined switch one of the phase leg $\mathrm{x}$ of the FCI $(\mathrm{Y}=[1 \ldots 4])$. The switch manage functions preserve acquire two values $S_{x y}=[0,1]$, i.e " 0 " and " 1 " the switch is off and on, in order. The switches another pairs of each phase-leg $\left(S_{x y}\right.$ and $S_{x y}$ ) activate and balancing the circuit. Each phase-leg can able to generate various output voltage levels. The various the potential output voltage levels are $0, \mathrm{Vdc} / 4$, $\mathrm{Vdc} / 2,3 \mathrm{Vdc} / 4$, and $\mathrm{Vdc}$.

Through the FCs $\left(i c_{x 1}, i c_{x 2}\right.$ and $\left.i c_{x 3}\right)$ can be written as:

$V_{x 0}=S_{x 4} V_{d s}+\left(S_{x 3}-S_{x 4}\right) V C_{x 3}+\left(S_{x 2}-S_{x 3}\right) V C_{x 2}$
$+\left(S_{x 1}-S_{x 2}\right) V C_{x 1}$

$i c_{x 1}=\left(s_{x 2}-s_{x 1}\right) i_{x}$

$i c_{x 2}=\left(S_{x 3}-S_{x 2}\right) i_{x}$

The successive switching states levels of all the possible combinations of various voltage from [0000] $\{0\}$ to [1111] $\{15\}$ for a five-level FCI inverter. The operation states between two successive switching states, as individual's transitions entail varying only one bit. at the same time as a result, they generate the minimum number of switching.

\subsection{Multilevel Modulation Techniques:}

Multilevel PWM techniques be able to be classifying as shown in Fig. 2, In the technical literature, three main modulation techniques are broadly used and adopted; multicarrier PWM, elimination selective harmonic, and space- vector PWM. Every one of them is extension of the usual two-level PWM method to higher number of levels. Among all these techniques, the multicarrier PWM is easier to put into practice and provides extremely excellent outcome. The multicarrier PWM method is advance classified into two categories, i.e. PSPWM and level shifted PWM (LSPWM). 


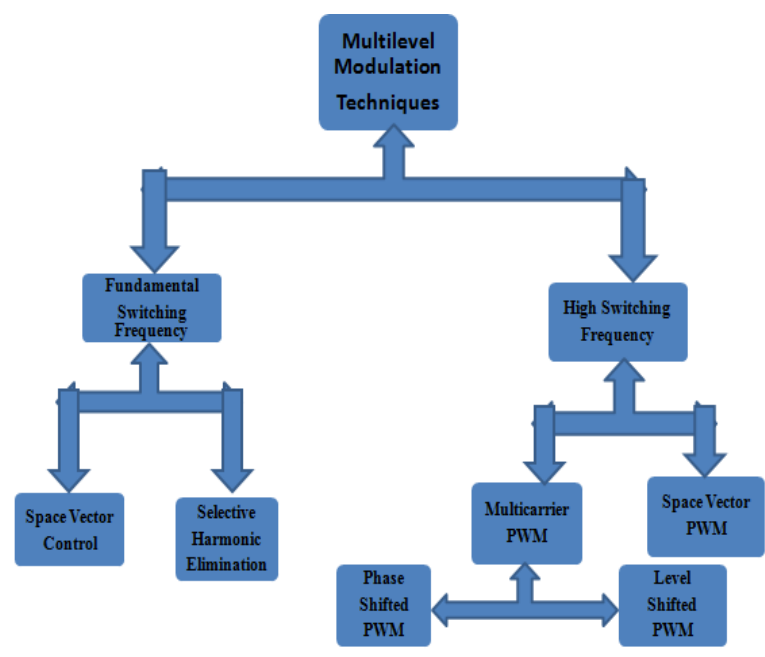

Fig. 2 classification of multilevel inverters and

$$
i c_{x 3}=\left(s_{x 4}-S_{x 3}\right) i_{x}
$$

Table .1 Five-Level FCI: During switching states the inverter operation Voltage, current condition and Effects on the FC Voltages

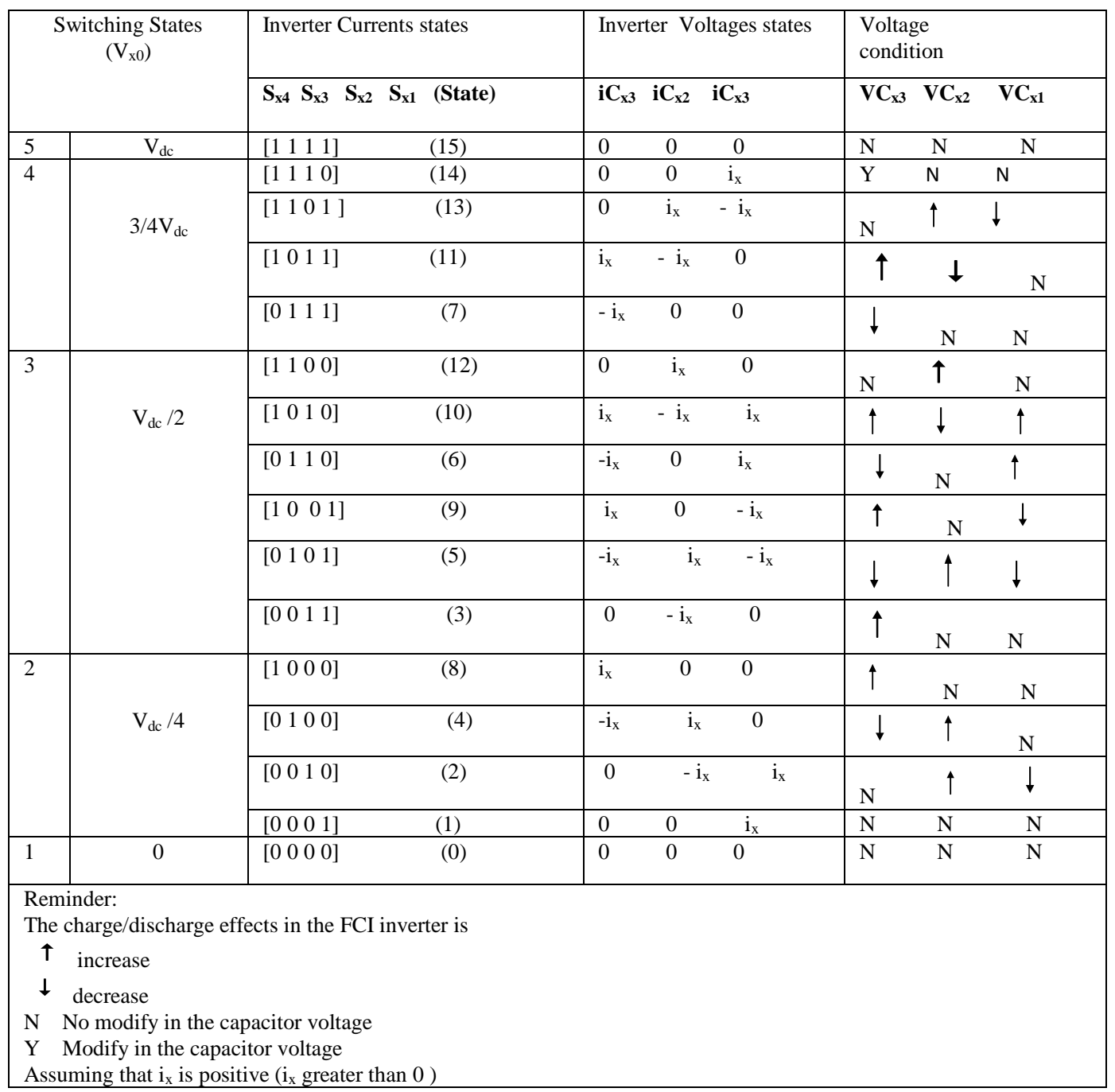




\subsection{PS-PWM:}

In multilevel inverters similar to the FCI and the SMC, each carrier of PS-PWM is related to a exacting power cell or pair of switches. In the case of a general n-level FCI, the carriers are phase shifted by $360^{\circ}=(n-1)$ in arrange to supply best possible stepped multilevel output voltage waveforms. By using control signal modulation like reference wave and carrier signals i.e PSPWM in the case of a five-level FCI. In this inverter, PSPWM requires four carriers of the same amplitude and frequency, which are phase-shifted by $90^{\circ}$ (Fig. 3, 4) among successive carrier signals.

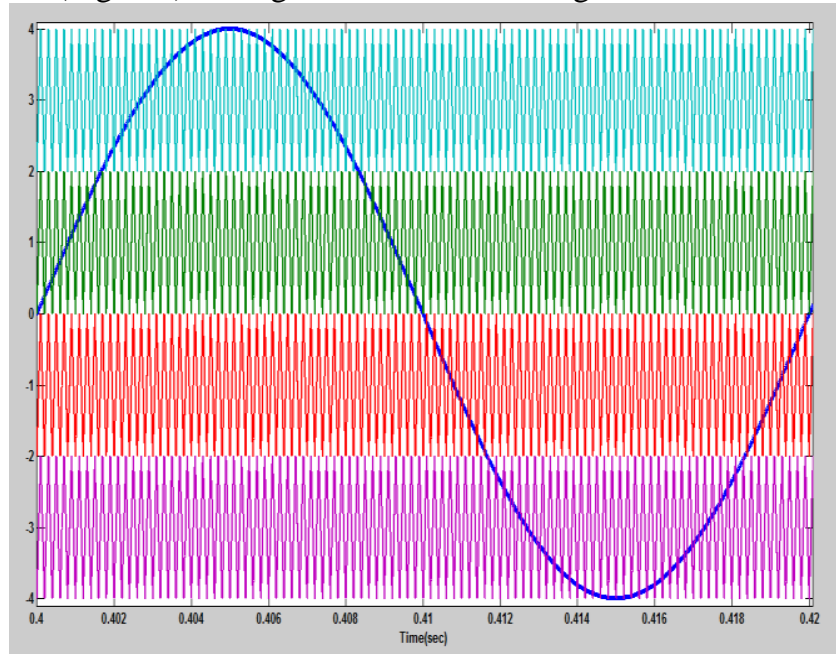

Fig.3 PSPWM method for five- level FCI, sinusoidal reference signal with carrier wave.

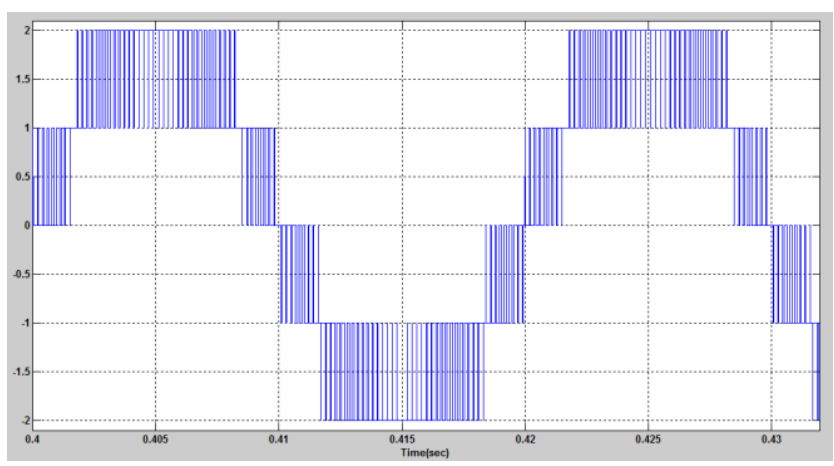

Fig.4 PSPWM Technique for five- level FCI, phases out put voltage.

Reference wave signal (Vxref ) normalize in the period $[-1,1]$ is compare among all six triangular carriers signals modulated , later connected FCI MLI inverter, it has to be generated as the output voltage. With PSPWM, the capacitor voltages are obviously balanced. On the other hand, the voltage matching progression is generally time-consuming parameters are depends on the loading setting. Hence, energetic flying capacitor voltage balancing methods can be investigated and recovered. The FC voltages to their reference levels through enhanced dynamics performance, particularly under transient conditions and non-linear loads.

\subsection{Fundamentals of the Voltage Balancing Method:}

The planned voltage matching process is developed based going on the investigation a generic cell sector of the FCI as given away in Fig. 5. From Equations (1.1) to (1.4), the current during a capacitor is represented by:

$$
i c_{x y}=\left(s_{x y+1}-s_{x y}\right) i_{x}
$$

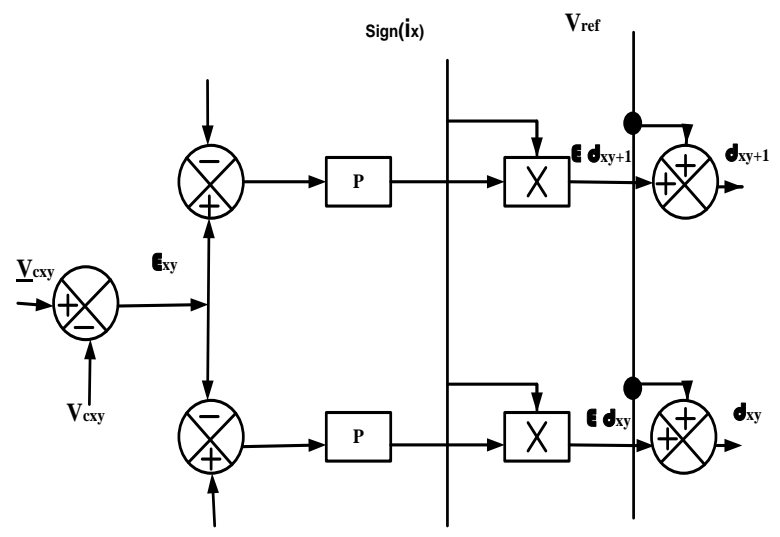

Fig. 5 FCs voltage balancing method based equations . It knows how to be observed that the current from end to end a capacitor is affect with the control signals related to the two contiguous switches. The locally-averaged illustration of the capacitor current in Equation (1.5) is designed over a switching period and is shown as:

$$
i c_{x y}=\left(d_{x y+1}-d_{x y}\right) i_{x}
$$

where $\mathrm{iC}_{\mathrm{xy}}$ and $\mathrm{ix}$ are the averaged currents of the capacitor $\mathrm{C}_{\mathrm{xy}}$ and the output current, correspondingly, and dxy+1 and $\mathrm{dx} y$ are the duty cycles of the switch $S_{x y}+1$ and $S_{x y}$, in that order.

Table. 2 FCI simulation circuit parameters

\begin{tabular}{|l|l|}
\hline FCI MLI Parameter & Value \\
\hline Dc-link bus voltage, $\mathrm{Vdc}$ & $48 \mathrm{v}$ \\
\hline $\mathrm{FCs}\left(\mathrm{C}_{\mathrm{x} 1}, \mathrm{C}_{\mathrm{x} 2}\right.$ and $\left.\mathrm{C}_{\mathrm{x} 3}\right)$ & $110 \mathrm{uf}$ \\
\hline Load resistance, $\mathrm{R}_{\mathrm{L}}$ & $20 \mathrm{ohms}$ \\
\hline Inductance, $\mathrm{L}$ & $8 \mathrm{mh}$ \\
\hline Carrier frequency $\left(\mathrm{f}_{\mathrm{c}}\right)$ & $5 \mathrm{kHz}$ \\
\hline Fundamental frequency,f & $50 \mathrm{~Hz}$ \\
\hline Frequency modulation index, $\mathrm{f}_{\mathrm{m}}$ & $40 \mathrm{~Hz}$ \\
\hline
\end{tabular}

\subsection{Dc-Dc Boost converter:}

The dc-dc boost converter is a well-known method; It has been analyzed with references [4]. The expand of the boost converter is:

$$
M_{\text {boost }}=\frac{V_{d c}}{V_{p v}}=\frac{1}{\left(1-D_{\text {boost }}\right)}
$$

Where Vpv is from solar PV panel of input voltage, Vdc is the dc link bus voltage. Vdc must give the suitable modulation indicator of the inverter. The voltage from PV-Array ( $\mathrm{Vpv}$ ) is between $\mathrm{Vpv}$ minimum and $\mathrm{Vpv}$ maximum which obtained the $\mathrm{D}_{\text {boost }}(\min )$ and $\mathrm{D}_{\text {boos }} \mathrm{t}(\max )$ as follow: 


$$
\begin{aligned}
& D_{\text {boost(min) }}=\frac{\left(V_{d c}-V_{p r(\max )}\right.}{V_{d c}} \\
& D_{\text {boost(max) }}=\frac{\mathbb{V}_{d c-} V_{p r(m i n)}}{V_{d c}}
\end{aligned}
$$

To minimization the $\mathrm{dc}$ to $\mathrm{dc}$ boost converter ripple current and voltage placed inductance and capacitor respectively like a passive filter placed from the PV-array.

Table 3. Specifications for 48v PV Panel 500W

\begin{tabular}{|l|c|c|}
\hline $\mathrm{P}_{\max }$ ( Watts) & 500 & \\
\hline OC voltage & 58.95 & \\
\hline Power at max. Voltage & 48.63 & \\
\hline SC current Max.power & 10.87 & \\
\hline $\begin{array}{l}\text { Current at } \\
\text { current }\end{array}$ & 10.28 & \\
\hline
\end{tabular}

\section{Closed-loop control of Multi-Level Inverter using Boost converter:}

In the present work, Boost converter based closed-loop control is proposed for MLI. The closed-loop control of MLI is achieved through the variation of the input voltage. It is a simple external control strategy for MLI using a solar PV based boost converter. In the work input voltage of $48 \mathrm{v}$ is obtained using solar panel with $1000 \mathrm{~W} / \mathrm{m}^{2}$ solar irradiation, $25^{0} \mathrm{C}$ temperature. The desired out is compared with the input voltage given to the MLI. The error voltage is given to the PID controller. The control voltage is used to drive the IGBT of the dc to dc Boost converter. The closed loop control strategy is shown in Fig, 6.

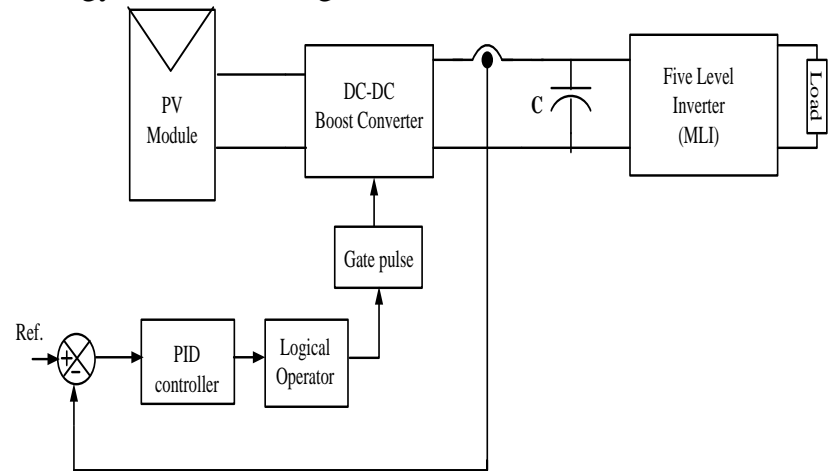

Fig.6 Closed-loop control strategy of MLI using Solar PV based Boost converter.

\section{SIMULATION RESULTS AND ANALYSIS:}

The proposed work is demonstrated with MATLAB simulations. Below figure shows the output voltage of the Solar PV based dc-dc boost converter.

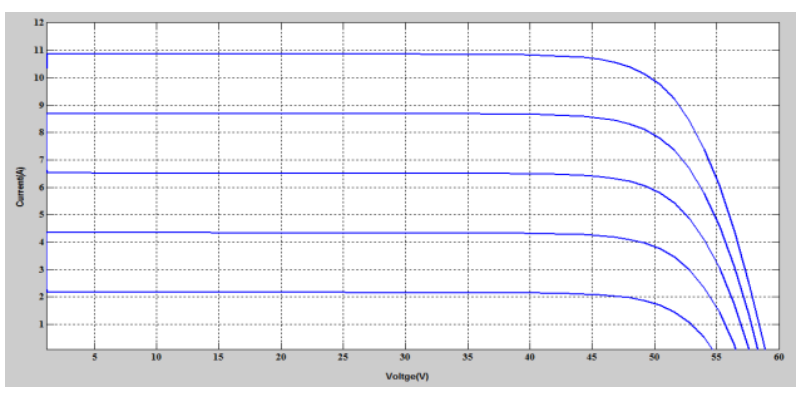

Fig. 10 (a) Solar PV I-V plots for different Irraditions (i.e 1000;800;600; 400;200 W/m ${ }^{2}$ ) From solar PV module modeling simulation results are obtained at different irradition condition I-V plot.
Fig. 10(b) Solar PV plots for different Irraditions (i.e 1000; 800; 600; 400;200 W/m $\mathrm{m}^{2}$ ),From solar PV module modeling simulation results are obtained at different irradition condition I-V plot.

Keeping the fixed input voltage i.e. $48 \mathrm{v}$ from solar PV module and the closed-loop is demonstrated for different reference voltages.

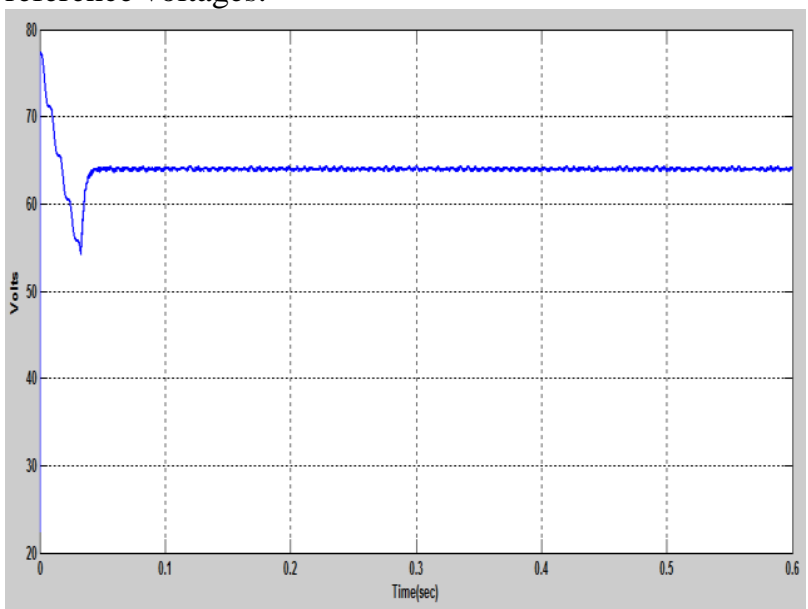

Fig.7 (a) Solar PV based Boost converter output voltage for reference voltage 64VFrom PV module maximum input voltage getting $48 \mathrm{~V}$ by using Boost converter obtained a constant $V_{d c}=64 \mathrm{~V}$.

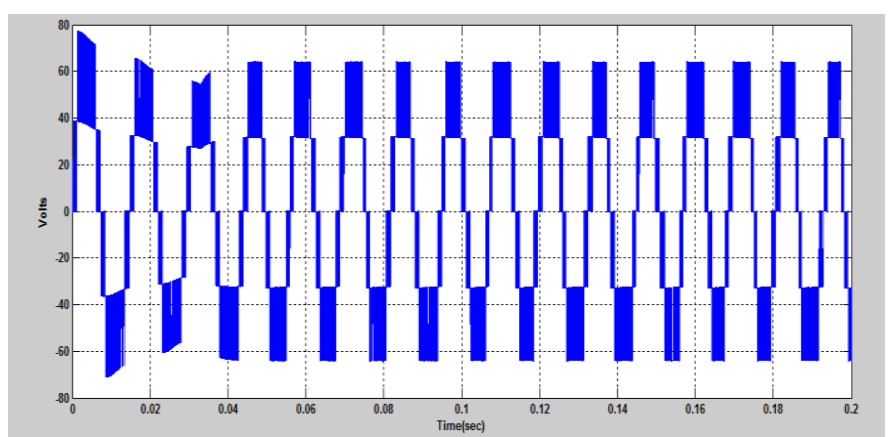

Fig.7 (b) Fist case FCI, boost converter input voltage is $48 \mathrm{~V}$ and FCI closed loop control corresponding voltage is $64 \mathrm{~V}$. 


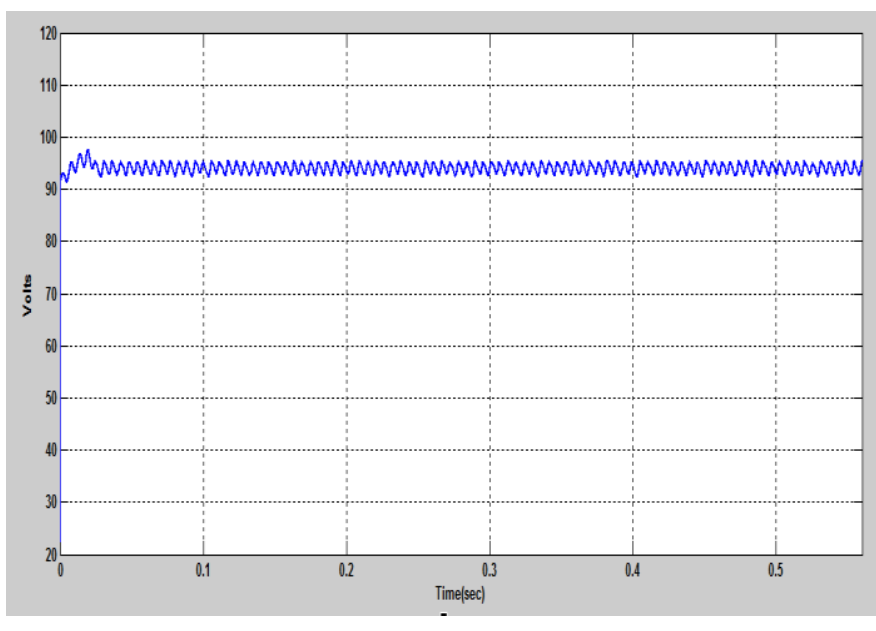

Fig.8 (a) Solar PV based Boost converter output voltage for reference voltage 94V From PV module maximum input voltage getting $48 \mathrm{v}$ by using Boost converter obtained a constant $V_{d c}=94 \mathrm{~V}$.

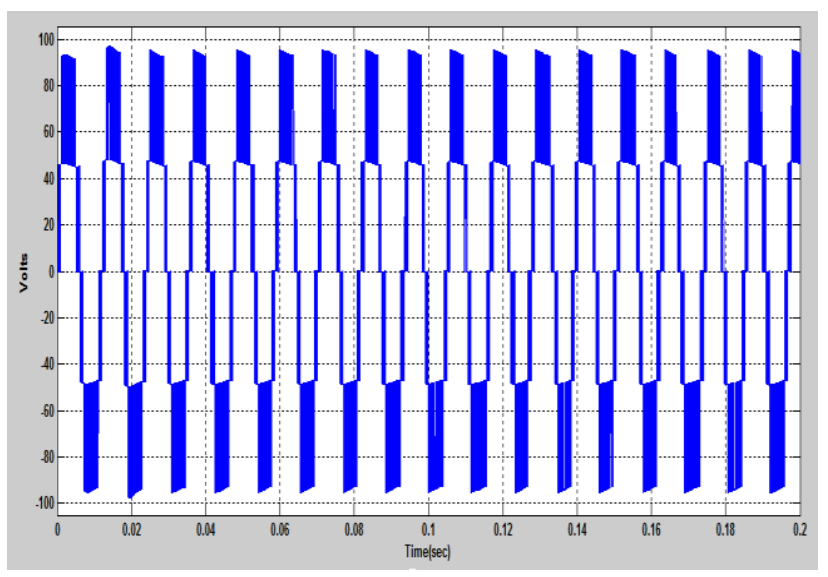

Fig.8 (b) Corresponding closed-loop control of MLI for $94 \mathrm{~V}$ voltage Second case FCI, boost converter input voltage is $48 \mathrm{v}$ and FCI closed loop control corresponding voltage is $94 \mathrm{~V}$.

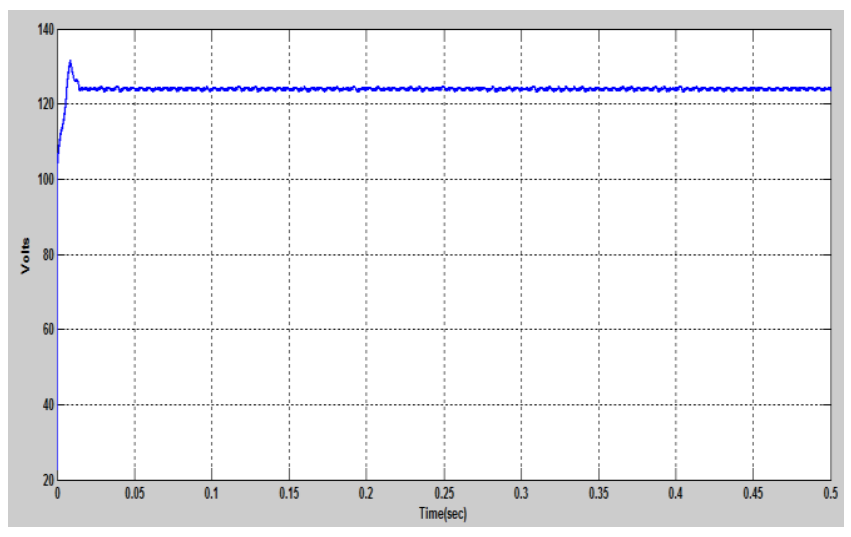

Fig.9 (a) Solar PV based Boost converter output voltage for reference voltage $124 \mathrm{~V}$ From $\mathrm{PV}$ module maximum input voltage getting $48 \mathrm{~V}$ by using Boost converter obtained a constant $V_{d c}=124 \mathrm{~V}$.

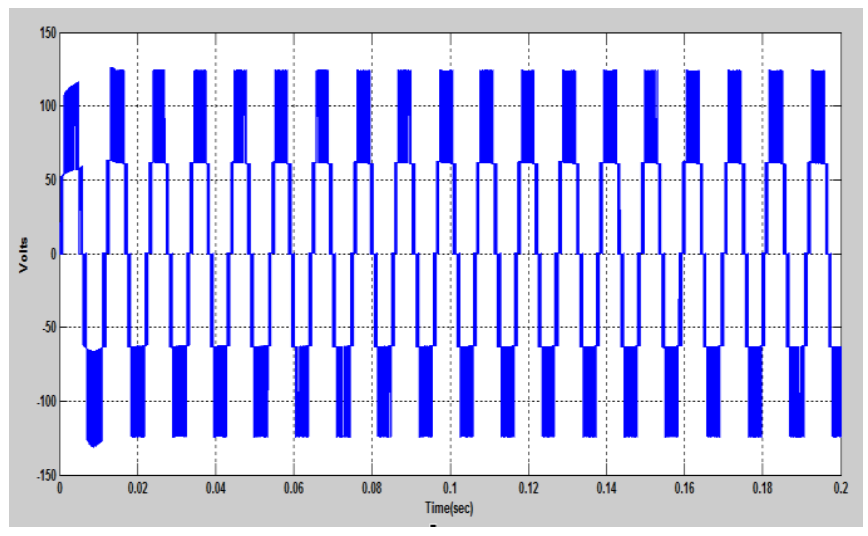

Fig.9(b) Corresponding closed loop control of MLI for

124 voltage Third case FCI, boost converter input voltage is $48 \mathrm{~V}$ and FCI closed loop control corresponding voltage is $124 \mathrm{~V}$.

\section{CONCLUSION:}

MLIs are growing importance in recent times due to their advantages of having high level output with minimized distortion levels. Among all MLIs, flying capacitor based MLIs are important for solar PV applications due to their inherent advantage of less distorting and more flexibility for closed loop operations. In this regard, FC based MLI with sinusoidal PWM technique has been simulated and a controller for voltage regulation has been designed. The closed-loop operation is carried out with input voltage control variation using a Solar PV based Boost converter. The simulation results using MATLAB/SIMULINK have been presented to prove the effectiveness of closed loop controller FC based MLI for solar applications for various changes in irradiance levels.

\section{References:}

1. MohanaSundar,Manoharan, Ashraf,ahmed, Joung-Hu Park,"a pv power conditioning system using nonregenerative single-sourced trinary asymmetric multilevel inverter with hybrid control scheme and reduced leakage current" IEEE Transactions on Power Electronics, Volume: 32 , Issue: 10 , pp: 7602 - 7614, Oct. 2017 .

2. Moacyr Aureliano Gomes de Brito; Luigi Galotto; Leonardo Poltronieri Sampaio ; Guilherme de Azevedo, "Evaluation of the Main MPPT Techniques for Photovoltaic Applications" : IEEE Transactions on IndustrialElectronics, Volume:60, Issue:3, pp: 1156 - 1167, March 2013.

3. Liwei Zhou ; Feng Gao ; Tao Xu," A Family of Neutral-Point-Clamped Circuits of Single-Phase PV Inverters:Generalized Principle and Implementation" IEEE Transactions on Power Electronics (Volume: 32 , Issue: 6 , pp: 4307 4319, June 2017 )

4. Priyabrata Shaw," Modelling and analysis of an analogue MPPT-based PV battery charging system utilising dc-dc boost converter" IET Renewable Power Generation (Volume: 13 , Issue: 11, pp: $1958-$ 1967, 8192019.

5. Arpan Hota , Sachin Jain , Vivek Agarwal," An Improved Three-Phase Five-Level Inverter Topology With Reduced Number of Switching Power Devices" IEEE Transactions on Industrial Electronics ,Volume: 65 , Issue: 4 , pp: 3296 - 3305, April 2018.

6. Jianzhong Zhang ; Shuai Xu ; Xing Hu ; Yaodong Zhu," Voltage Balancing Control of Hybrid Stacked Multicell Inverters Based on Modified Phase-Shifted PWM" IEEE Access , Volume:7 pp: 25589 25602, 21 February 2019. 
7. Jianzhong Zhang ; Shuai Xu ; Xing Hu ; Yaodong Zhu," Voltage Balancing Control of Hybrid Stacked Multicell Inverters Based on Modified Phase-Shifted PWM" IEEE Access,Volume: 7, pp: $25589-25602,21$ February 2019.

8. Potnuru, Devendra, Javvaji Anilkumar, and A. P. Srikakulam. "A DC-DC inverter for low power applications using Arduino UnoMicrocontroller." International Journal of Pure and Applied Mathematics 114, no. 7 2017: 123-127, 2017. 